\section{Commentary: An ounce of prevention}

\author{
Lawrence M. Wei, MD, and Vinay Badhwar, MD
}

In this issue of JTCVS Techniques, Burke and colleagues ${ }^{1}$ present a timely review of surgery following transcatheter aortic valve replacement (TAVR). As TAVR becomes more prevalent and its application attempts to expand to younger and lower-risk patients, cardiac surgeons must be equipped to address acute and late failures that require surgical intervention. The innovation of TAVR has caused a new surgical pathology, and our colleagues ${ }^{1}$ have provided a pathway to prepare for what is come.

Acute "bailout" surgery for intraprocedural complications of TAVR has an incidence of $<4 \%$ but significant mortality and morbidity. ${ }^{2,3}$ Cardiac perforation, tamponade, device migration, and annular rupture are the most common reasons for intervention, with aortic dissection and coronary occlusion requiring surgery less common. ${ }^{4}$ Although perforation is a risk of any transcatheter procedure, device migration is potentially preventable, as it is clearly associated with certain factors, including aortic insufficiency, large annuli, minimal annular calcification, non-coaxial horizontal alignment, and bicuspid valve pathology, that all tend to favor surgical aortic valve replacement (SAVR) ${ }^{5,6}$ Avoidance of TAVR for such patients, particularly if low to intermediate risk, would mitigate bailout and may increase a program's quality outcomes. As we soon enter a period of TAVR public reporting, perhaps teams will be more careful in selecting TAVR over SAVR.

Current support for TAVR in low-risk patients is based on the PARTNER 3 trial (SAPIEN S3, Edwards Lifesciences,

\footnotetext{
From the Department of Cardiovascular and Thoracic Surgery, West Virginia University, Morgantown, WVa.

Disclosures: The authors reported no conflicts of interest.

The Journal policy requires editors and reviewers to disclose conflicts of interest and to decline handling or reviewing manuscripts for which they may have a conflict of interest. The editors and reviewers of this article have no conflicts of interest.

Received for publication Jan 10, 2021; revisions received Jan 10, 2021; accepted for publication Jan 13, 2021; available ahead of print Jan 20, 2021.

Address for reprints: Vinay Badhwar, MD, Department of Cardiovascular and Thoracic Surgery, West Virginia University, Morgantown, WV 26506 (E-mail: vinay.badhwar@wvumedicine.org).

JTCVS Techniques 2021;6:59-60

2666-2507

Copyright (C) 2021 The Authors. Published by Elsevier Inc. on behalf of The American Association for Thoracic Surgery. This is an open access article under the CC BY license (http://creativecommons.org/licenses/by/4.0/).

https://doi.org/10.1016/j.xjtc.2021.01.015
}

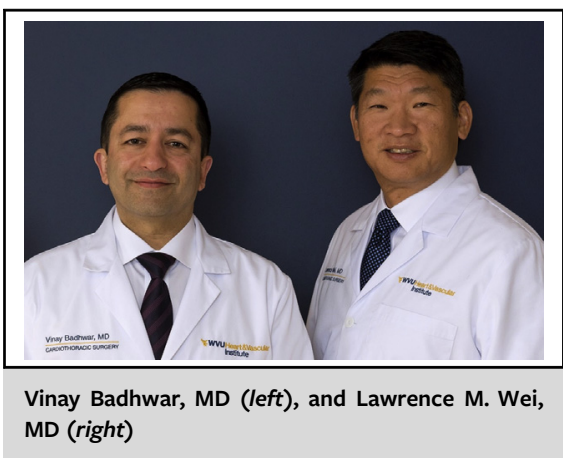

CENTRAL MESSAGE

Preventing the need for reoperation following transcatheter aortic valve replacement begins with careful patient selection and weighing other durable low-risk surgical alternatives.

Irvine, Calif) and Evolut Low Risk trial (CoreValve, Medtronic, Minneapolis, Minn). ${ }^{7,8}$ The PARTNER 3 trial included rehospitalization, stroke, and all-cause mortality in the composite end point and the Evolut Low Risk trial employed a composite end point of stroke and all-cause mortality with noninferiority to SAVR. Although both trials met their designed primary end points, isolated mortality of TAVR and SAVR were similar. Importantly, both trials excluded many of the patients who now are being referred for TAVR (younger, bicuspid pathology, subvalvular calcium, anatomic size exclusions). With more young and low-risk patients being referred for TAVR, it is incumbent upon the multidisciplinary heart team to consider carefully and objectively whether TAVR is reasonable when low-risk, minimally invasive SAVR is available. ${ }^{6}$ Preventing a complication by avoiding an inappropriate procedure is preferable to managing it with a high-risk emergent intervention.

Burke and colleagues ${ }^{1}$ appropriately emphasize the importance of formal discussion by the multidisciplinary heart team with the patient and family of the risks of complications as well as candidacy and prognosis for salvage interventions. Candidacy for bailout and detailed plans for the approach should be reviewed by the procedural team as part of the preprocedure briefing. Clearly defining which patients are not candidates for bailout procedures will help to prevent futile salvage operations. The authors ${ }^{1}$ nicely outline the technical challenges, such as adherence of the 


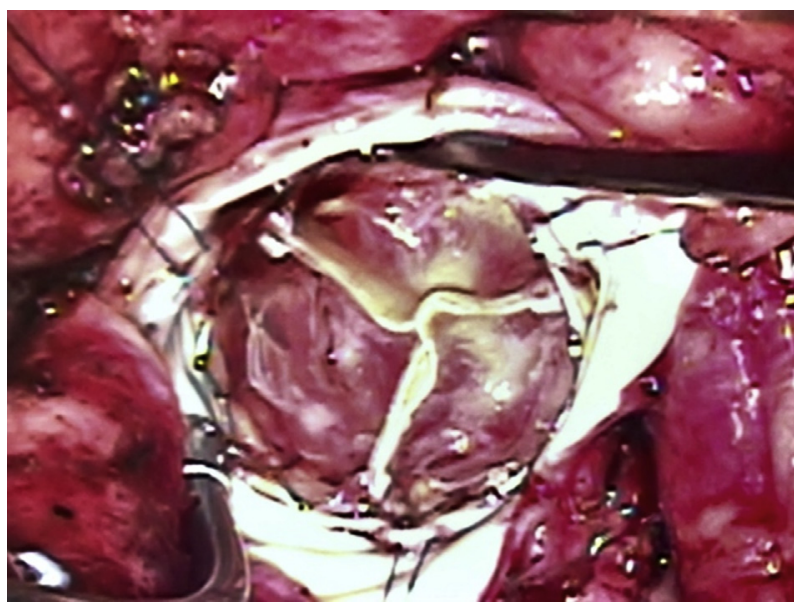

FIGURE 1. Reoperation for prematurely thrombosed and stenotic transcatheter aortic valve replacement in a previously low-risk 71-year-old man.

prosthesis to the native leaflets and ingrowth of the prosthetic material into the subannular and supra-annular tissue, especially with a self-expanding prosthesis. Aortic root replacement, with its attendant complexity and greater risk, frequently is required. These are issues that do not occur with a conventional redo-SAVR operation.

Paravalvular leak (PVL), prosthetic valve endocarditis, structural and hemodynamic valve deterioration, thrombosis, and late migration are the usual indications for late surgical intervention following TAVR. Although the incidence and severity of PVLs has decreased with newer generations of TAVR prostheses, they still occur with greater frequency than with SAVR and not all are repairable with catheter-based closure devices. ${ }^{7-10}$

The long-term durability of TAVR prostheses, still an unknown, is unlikely to exceed nor match that of SAVR. Fiveyear data on intermediate-risk patients show rates of PVL, need for reintervention, and longitudinal results that may begin to favor SAVR over TAVR. ${ }^{9}$ TAVR, the revolutionary technology originally intended as therapy for patients too old or frail to be surgical candidates and for whom durability was irrelevant, now is being applied to younger patients who are at low risk for surgical procedures and for whom durability is the most important consideration. Although the index procedural risk may be similar for TAVR and SAVR, the long-term outlook must factor in the shorter durability of the TAVR prosthesis and the greater risk of repeat procedures. Some patients with degenerated TAVR prostheses will be able to undergo valve-in-valve TAVR, a procedure with mixed results and even less durability data than primary TAVR, ${ }^{10,11}$ but most will require reoperative SAVR and be subject to the increased reoperative surgical risks (Figure 1). Performing low-risk SAVR as the index procedure in a younger patient will reduce the likelihood of greater risk reoperation later in life.

Newer approaches to SAVR, including robotically assisted minimally invasive AVR, may offer reduced morbidity, shorter hospitalization, and more rapid recovery while providing the proven track record of conventional SAVR prostheses and elimination of the short- and long-term risks of reoperation for failed TAVR. ${ }^{6}$ For some young low-risk patients, it is unconscionable to sacrifice the long-term benefits of SAVR for the short-term convenience of TAVR. Burke and colleagues ${ }^{1}$ are to be commended for providing this frank commentary on the risks of surgery following TAVR. Their findings support the adage that "an ounce of prevention" with careful selection of SAVR over TAVR for those with predictable features, "is worth a pound of cure" to avoid early reoperation.

\section{References}

1. Burke CR, Oyetunji SO, Aldea GS. Surgery after transcatheter aortic valve interventions. J Thorac Cardiovasc Surg Tech. 2021;6:54-8.

2. Hein R, Abdel-Wahab M, Sievert H, Kuck KH, Voehringer M, Hambrecht R, et al. Outcome of patients after emergency conversion from transcatheter aortic valve implantation to surgery. EuroIntervention. 2013;9:446-51.

3. Walther T, Hamm CW, Schuler G, Berkowitsch A, Kötting J, Mangner N, et al. Perioperative results and complications in 15,964 transcatheter aortic valve replacements: prospective data from the GARY registry. J Am Coll Cardiol. 2015;65:2173-80.

4. Pineda AM, Harrison JK, Kleiman NS, Rihal CS, Kodali SK, Kirtane AJ, et al. Incidence and outcomes of surgical bailout during TAVR: insights from the STS/ACC TVT Registry. JACC Cardiovasc Interv. 2019;12:1751-64.

5. Kim WK, Schäfer U, Tchetche D, Nef H, Arnold M, Avanzas P, et al. Incidence and outcome of peri-procedural transcatheter heart valve embolization and migration: the TRAVEL registry (TranscatheteR HeArt Valve EmboLization and Migration). Eur Heart J. 2019;40:3156-65.

6. Badhwar V, Wei LM, Cook CC, Hayanga JWA, Daggubati R, Sengupta PP, et al. Robotic aortic valve replacement. J Thorac Cardiovasc Surg. November 16, 2020 [Epub ahead of print].

7. Mack MJ, Leon MB, Thourani VH, Makkar R, Kodali SK, Russo M, et al. Transcatheter aortic-valve replacement with a balloon-expandable valve in low-risk patients. N Engl J Med. 2019;380:1695-705.

8. Popma JJ, Deeb GM, Yakubov SJ, Mumtaz M, Gada H, O'Hair D, et al. Transcatheter aortic-valve replacement with a self-expanding valve in low-risk patients. N Engl J Med. 2019;380:1706-15.

9. Makkar RR, Thourani VH, Mack MJ, Kodali SK, Kapadia S, Webb JG, et al. Five-year outcomes of transcatheter or surgical aortic-valve replacement. $N$ Engl J Med. 2020;382:799-809.

10. Clerfond G, Pereira B, Innorta A, Motreff P, Gilard M, Laskar M, et al. Comparison of outcomes after one-versus-two transcatheter aortic valve implantation during a same procedure (from the FRANCE2 Registry). Am J Cardiol. 2015; 115:1273-80.

11. Makkar RR, Jilaihawi H, Chakravarty T, Fontana GP, Kapadia S, Babaliaros V, et al. Determinants and outcomes of acute transcatheter valve-in-valve therapy or embolization: a study of multiple valve implants in the U.S. PARTNER trial (Placement of AoRTic TraNscathetER Valve Trial Edwards SAPIEN Transcatheter Heart Valve). J Am Coll Cardiol. 2013;62:418-30. 